\title{
Crisis y refuncionalización de las redes de reciprocidad familiares: el caso de sectores medios en la Ciudad de México
}

\author{
José Guadalupe Rivera GonzÁlez*
}

\begin{abstract}
Some of the strategies with which families have been able to adapt to contexts characterised by work scarcity and an unfavourable economical environment came up as a result of their successful participation on a nucleus of intra -and extra- family networks of solidarity. This provided them with an important exchange of resources and favours that hel ped them to face their needs. H owever, given that the last few years have been characterised by work uncertainty, the loss of purchasing power of the income, and in general, the lack of dynamism in some variables of the national economy, it is important to analyse if families are still able to participate in a networks that allow for social exchange, reciprocity and mutual help. The analysis of the latter is the aim of this work.
\end{abstract}

Keywords family network, economical crisis, middle sector, unemployment, reciprocity.

\section{Resumen}

Algunas de las estrategias con las cuales las familias han conseguido adaptarse a contextos caracterizados por la precariedad laboral y a un entorno económico poco favorable surgieron a partir de que esas familias lograron asegurar su participación en un núcleo de redes de solidaridad intra y extrafamiliares que les brindó un importante intercambio de recursos y favores con los que hicieron frente a sus necesidades. Sin embargo, después de que los últimos años se han caracterizado por la incertidumbre laboral, la pérdida del poder adquisitivo de los ingresos y, en términos generales, la fal ta de dinamismo de algunas variables de la economía nacional, se vuelve apremiante analizar si las familias estarán en condiciones de seguir participando en un conjunto de redes que les permita el intercambio social, la reciprocidad y la ayuda mutua. El análisis de estos últimos planteamientos es el objetivo de este trabajo.

Palabras clave: redes familiares, crisis económica, sectores medios, desempleo, reciprocidad. 


\section{Preámbulo}

A partir de un amplio y nutrido conjunto de etnografías que se han realizado en M éxico y en otros países en torno a diversos fenómenos relacionados con el mundo de la familia en los ámbitos rural y urbano, se han evidenciado la complejidad y las diversas variaciones que operan en la organización interna del núcleo familiar para amortiguar los efectos de los acelerados procesos de cambio sociocultural que experimenta la sociedad en su conjunto. En ese mismo sentido se han destacado la flexibilidad y la enorme capacidad de adaptación y respuesta de la familia en distintos momentos de crisis y ajuste de la actividad económica. Por ejemplo, algunas de las estrategias empleadas por las familias para adaptarse a contextos caracterizados por la precariedad laboral y a un entorno económico poco favorable, o incluso para enfrentar las obligaciones y los requisitos de la participación en la vida ritual en comunidades campesinas e indígenas, fueron posibles a partir de que se logró asegurar la participación en un importante núcleo de redes de solidaridad intra y extrafamiliares (Arizpe, 1973 y 1978; Alonso y Aguilar, 1980; Bazán, 1996; Benería y Roldán, 1987; Carrasco, 1998; Estrada, 1996 y 1999; Foster, 1972; González de la Rocha, 1986; Kemper, 1976; Adler Lomnitz, 1987; Adler Lomnitz y Pérez Lizaur, 1993; Lewis, 1993; N utini, 1968; Robichaux, 2002; Selby et al., 1994; Taggart, 1975).

En este mismo sentido, los resultados de las anteriores investigaciones muestran que para las familias tener una participación en dichas redes de solidaridad fue determinante, entre otras cosas, para tener acceso a información acerca de posibles empleos y obtener apoyo en el cuidado y manutención de algunos miembros de la familia (principalmente de menores de edad y personas adultas mayores). Sin embargo, los beneficios de las redes sociales no estuvieron reducidos exclusivamente a las familias de los sectores más pobres. Por ejemplo, el hecho de que algunos cónyuges contaran con empleos seguros y bien remunerados en el sector público o privado sirvió como un aliciente para que las familias pudieran tener asegurada una activa participación en esas formas de intercambio. Por lo tanto, entre las familias más pobres lo que se intercambia y comparte son los gastos y las funciones domésticas de diversa índole, mientras que entre las familias de los sectores medios y altos se intercambia información valiosa para posibles inversiones, apoyo entre pro- 
fesionales, consultas sobre negocios, respaldo político, etcétera; es decir, se puede hablar de que en esas redes familiares se comparte, entre otras cosas, información para conformar grupos y alianzas de poder.

Una de las modalidades de participación en esas redes de intercambio era la asistencia a reuniones de carácter ritual-festivo, las cuales contribuían a afianzar la participación de la familia en circunstancias particulares y a que ésta formara parte de grupos donde se circulaba información y además se redistribuían servicios y favores. Esas estrategias se habían consolidado como el principal recurso con el cual las familias habían enfrentado situaciones de escasez de empleo y de salarios y demás efectos de las cada vez más frecuentes crisis económicas. En muchos sentidos, esas estrategias de ayuda aparecían como el último y, en el caso de las familias más pobres, tal vez como el único medio por el cual podían satisfacerse las necesidades básicas de las familias, así como también las de otros integrantes.

Sin embargo, después de que los últimos años se han caracterizado por la incertidumbre laboral, la pérdida del poder adquisitivo de los ingresos y, en términos generales, la falta de dinamismo por parte de algunas variables de la economía nacional, ${ }^{1}$ las cuales han traído como consecuencia un importante deterioro en las condiciones de vida de la mayoría de las familias en M éxico, planteo las siguientes preguntas: ¿seguirán siendo funcionales las redes familiares y las estrategias de solidaridad y reciprocidad después de dos décadas de crisis y de la aplicación de políticas y programas de ajuste? ¿H asta qué punto puede esa situación estar contribuyendo a generar un proceso de recomposición de las relaciones sociales que se construyen tanto dentro como fuera de las familias? ¿Q ué prácticas relacionadas con la participación en las redes familiares y extrafamiliares se han tenido que transformar parcialmente o se han tenido que ver sus-

${ }^{1}$ Cabe señalar que la crisis de 1994 y sus devastadores efectos entre la mayoría de la población tenían como antecedente la aplicación sistemática de políticas y programas de ajuste que se pusieron en marcha inmediatamente después de la crisis de 1982 y que estaban encaminados a contrarrestar los efectos de la creciente apertura de la economía nacional a la influencia e injerencia de los mercados internacionales. Desde 1982, la mayoría de los trabajadores del país tuvieron que enfrentar la pérdida del poder adquisitivo de los salarios, haciéndose la experiencia del desempleo cada vez más frecuente ante un mercado laboral en franca crisis, de tal manera que las actividades informales o por cuenta propia se hicieron también cada vez más constantes y comunes entre diversos sectores de la población, incluidos los sectores medios (para esto último, véase Esteinou, 1996). 
tituidas de manera momentánea 0 definitiva? ¿Estarán generándose nuevas modalidades de intercambio y de reciprocidad dentro y fuera de las familias? ¿Cuál fue la experiencia de aquellas familias donde los efectos de la crisis y los programas de ajuste no se materializaron en una situación de desempleo de uno o más de sus miembros o en la reducción significativa de sus ingresos salariales, sino que más bien experimentaron todo lo contrario: los miembros que laboraban se consolidaron en el empleo y se obtuvieron mayores ingresos?

En la primera parte del trabajo se examina el grado de participación que mantenían las familias encuestadas y entrevistadas dentro de un conjunto de estrategias de ayuda mutua, solidaridad y reciprocidad en momentos previos a la crisis económica de 1994 y en los años posteriores a esa experiencia; después se centra el análisis en la descripción de las transformaciones que sufrieron esas mismas familias con el impacto de los llamados errores de diciembre ${ }^{2}$ y de los programas de ajuste implantados por el gobierno federal para hacer frente a esa situación.

\footnotetext{
${ }^{2}$ Una de las manifestaciones inmediatas de la crisis económica de 1994, entre las familias estudiadas, fue el desempleo. Los resultados de las 110 (100\%) familias a las cuales se les aplicó la encuesta mostraron que en 34 de ellas (31\%), al menos uno de sus miembros perdió temporalmente el empleo. Además, la distribución de las personas que perdieron su trabajo se dio de la siguiente manera: en 17 familias fue el esposo el desempleado, en otras cuatro fue la esposa, y en las 13 familias restantes fue alguno de los hijos. Estas acciones tuvieron en su mayoría una relación directa con la situación del deterioro que experimentó la economía a partir de cierres temporales o definitivos de empresas, e incluso de talleres o empresas y negocios familiares. 0 tro de los efectos inmediatos de la crisis y de los programas de ajuste instrumentados por parte de las autoridades económicas fueron los incrementos en los costos de los servicios proporcionados por el gobierno, lo cual desencadenaría una avalancha en el precio de diversos productos de la canasta básica. Esta situación también terminaría impactando de forma negativa entre aquellos miembros de la familia que no habían perdido el empleo, pero cuyos ingresos se vieron mermados como resultado de la inflación, que para el año de 1995 fue de 52\%. Para muchos más, la crisis se materializó en el problema de cartera vencida, lo cual representó una carga muy pesada, ya que los pagos mensuales de los intereses se incrementaron de manera significativa en un lapso relativamente corto, quedando miles de familias sin posibilidades de seguir realizando sus depósitos de manera puntual, lo cual terminó poniendo en peligro, en algunos casos, la posesión del patrimonio familiar. Es decir, el panorama para muchas de las familias aquí estudiadas resultó ser bastante problemático; la constante para ellas, a pesar de las diferencias naturales, fue la escasez de los ingresos para hacer frente a necesidades como el pago de servicios (salud, educación, teléfono, impuestos, etc.) y otros compromisos adquiridos con anterioridad (como fueron las deudas con los bancos).
} 


\section{Características de la población estudiada}

El grueso de la información que sirve de base para el presente artículo se obtuvo en dos periodos de trabajo de campo. ${ }^{3}$ El primero se desarrolló durante los meses de mayo a octubre de 1997, mientras que un segundo periodo abarcó de enero a mayo de 1998. Durante ese tiempo se aplicó una encuesta a un total de 110 familias. Además, las familias objeto del análisis fueron identificadas como pertenecientes a los sectores medios ${ }^{4}$ con el siguiente criterio: se privilegió el hecho de que los jefes de familia, o aquellos otros miembros que laboraran, lo hicieran en actividades no manuales en el sector público o privado; también se estableció que

\section{C uadro 1 \\ D istribución de las familias encuestadas según las etapas del ciclo doméstico}

\begin{tabular}{lrr}
\hline Formación & 33 familias & $30 \%$ \\
Consolidación & 65 familias & $59 \%$ \\
Reemplazo & 12 familias & $11 \%$ \\
Total & 110 familias & $100 \%$ \\
\hline
\end{tabular}

Fuente: Encuesta aplicada a las familias durante el trabajo de campo.

\footnotetext{
${ }^{3}$ Parte de la información que aquí se analiza fue presentada como resultado de una investigación más amplia que se presentó para obtener el grado de doctor en ciencias antropológicas en junio de 2004, en el Departamento de Antropología Social de la UAM ı. La investigación de campo se realizó con el apoyo económico de una beca-crédito otorgada por el Consejo Nacional de Ciencia y Tecnología. La dirección del proyecto estuvo a cargo de la Dra. M argarita Estrada, investigadora del Centro de Investigaciones y Estudios Superiores en Antropología Social, D.F.

${ }^{4}$ Parto de la diferenciación conceptual elaborada por Ralph Dahrendorf (1979), quien plantea que un sector social es una categoría de personas que, en atención a una serie de características de posición, se asumen a partir de considerar la importancia de variables como: ingresos obtenidos, prestigio, tipo de vida etc. En este sentido, sector es un concepto descriptivo de ordenación. Clase social es, por el contrario, una categoría analítica que sólo adquiere su pleno sentido en relación con una teoría de clases. Las clases son agrupaciones de intereses que surgen de ciertas contradicciones estructurales $y$, como tales, intervienen en conflictos sociales y contribuyen a las transformaciones de las estructuras.

A estos planteamientos agregaremos algunos señalamientos elaborados por $\mathrm{M}$ ax Weber (1979).

Este autor había reconocido también una gama variada de sectores sociales, los cuales se distinguen principalmente a partir de dos aspectos importantes que no se reducen única y exclusivamente a factores de índole económica. Las variables señaladas por Weber son:
}

La propiedad-inversión.

Los servicios que son ofrecidos en el mercado. 


\section{C uadro 2 \\ Distribución de los miembros de las familias encuestadas según el grado de escolaridad alcanzado}

\begin{tabular}{lrr}
\hline Preescolar & 8 & $2 \%$ \\
Primaria & 80 & $18 \%$ \\
Secundaria & 57 & $13 \%$ \\
Preparatoria & 68 & $15 \%$ \\
Universidad & 171 & $39 \%$ \\
Carrera técnica & 41 & $9 \%$ \\
Posgrado & 13 & $3 \%$ \\
Total & 438 & $100 \%$ \\
\hline
\end{tabular}

Fuente: Encuesta aplicada a las familias durante el trabajo de campo.

los cónyuges tuvieran una educación de nivel medio o superior, e incluso encontramos casos de cónyuges con estudios de nivel de posgrado (véase información del cuadro 2). Por lo tanto, trabajamos con personas que obtenían una remuneración más alta que la de los trabajadores de los sectores populares.

Se trabajó principalmente con maestros, oficinistas, servidores públicos 0 privados y profesionistas independientes (véase información del cuadro 3). Un primer conjunto de encuestas se aplicó a un total de 30 familias en las cuales alguno de sus miembros enfrentaba una situación de cartera vencida con alguna ins-

Estos dos puntos permiten hablar de la presencia de varios sectores sociales, debido al uso y significado distintivo que harán los consumidores de diversos productos y servicios. Este hecho motivará, entre otras cosas, la conformación de los sectores medios. O tras de las características importantes que señaló Weber en relación con la existencia de los sectores medios son:

No son dueños de los medios de producción, pero a la vez poseen ciertas habilidades que son el producto de una alta escolaridad. Conocimientos y habilidades que jugarán un papel importante en la determinación y la posición que ocupan esos sectores en la estructura social.

El mismo Max Weber planteó que la posición de los individuos dentro de la estructura social no será construida únicamente como resultado de su inserción o posición en torno a las relaciones económicas de producción. Aspectos como el estilo de vida y los patrones de consumo, que anteriormente aparecían como secundarios en la determinación social, servirán y determinarán la posición de los individuos dentro una estructura social más amplia.

Así pues, la utilización del concepto de sector social implica el reconocimiento, en su determinación, de una amplia gama de variables, no sólo de la económica. Es decir, la utilización del concepto de sector social nos llevará a reconocer la importancia que tienen variables como la educación, el consumo, los hábitos y los estilos de vida, los cuales se pueden considerar como verdaderos confirmadores y determinantes en la estructura social, y particularmente el reconocimiento de lo que aquí consideraremos como los sectores medios (Weber, 1979; Bourdieu, 1988 y 1990; Douglas e Isherwood, 1990). 


\section{C uadro 3 \\ Situación de la población encuestada que realizaba alguna actividad laboral}

\begin{tabular}{lrr}
\hline Patrón & 19 & $10 \%$ \\
Trabajador por su cuenta & 32 & $17 \%$ \\
Empleado & 138 & $70 \%$ \\
Trabajo sin pago & 6 & $3 \%$ \\
Total & 195 & $100 \%$ \\
\hline
\end{tabular}

Fuente: Encuesta aplicada a las familias durante el trabajo de campo.

titución bancaria o con algún particular. Este grupo de familias, al momento de aplicársele la encuesta, formaba parte de dos organizaciones de deudores: El Barzón M etropolitano y la Asamblea Ciudadana de Deudores de la Banca (ACDB). ${ }^{5}$ Un segundo conjunto de encuestas se aplicó a dos grupos de estudiantes de nivel superior: el primero formaba parte de una institución de enseñanza pública (34 encuestas) y el segundo realizaba estudios en una universidad privada (15 encuestas). El tercer grupo de encuestas se aplicó a un grupo de familias que se encontraban viviendo en una unidad habitacional, Villa Panamericana, ubicada en el sur de la Ciudad de M éxico (31 encuestas). Una vez que se practicó la encuesta, y con los datos de ella resultantes, se procedió a seleccionar a 40 familias con las cuales se realizó una fase de trabajo de campo; de allí se obtuvo información con más detalle y profundidad en lo relacionado con las experiencias de vida cotidianas.

\section{La funcionalidad de las redes familiares y de las estrategias de ayuda mutua y reciprocidad}

La clásica etnografía de Larissa Adler Lomnitz (1987), Cerrada del Cóndor, ofreció una muestra contundente de la flexibilidad y de los recursos con que contaban las familias pobres para asegurar su sobrevivencia ante un contexto económico desfavorable. La autora planteó que una de las condiciones básicas o funda-

${ }^{5}$ Cabe señalar que estudiosos de los movimientos de deudores de la banca han destacado el carácter policlasista de los mismos (M estries, 1995; Grammont, 2001). Por ejemplo, el movimiento de El Barzón, de ser en sus inicios un movimiento de productores rurales, se amplió para convertirse, con la agudización de la crisis, en un movimiento que integraba en su seno tanto a empresarios como a profesionistas y comerciantes. De igual forma, otros análisis realizados acerca de EI Barzón señalan que la presencia de esa organización en ámbitos netamente urbanos se había dado como un espacio que aglutinaba dentro de sus filas fundamentalmente a pequeños y medianos 
mentales para el establecimiento de las redes de reciprocidad entre los vecinos de esa barriada, era que esas redes se establecieron a partir de la existencia de una relación de parentesco directa entre sus miembros. Sin embargo, el parentesco directo o de sangre no era el único requisito para ser parte activa de una de las redes. Las relaciones basadas en valores como la amistad, la confianza, el cuatismo, el compadrazgo y la vecindad también contribuían al establecimiento de redes, las cuales aportaban al mejoramiento de las precarias condiciones de vida de la mayoría de los habitantes de la barriada.

O tro de los elementos fundamentales señalados por Adler Lomnitz fue que la mayoría de las relaciones que se llegaban a establecer entre los miembros de las redes familiares se constituían a partir de un vínculo de reciprocidad entre pares. Esa reciprocidad se entendía a partir de una situación de igualdad, en términos económicos y culturales. La igualdad económica de las partes evitaba que se generaran relaciones de dependencia o de patrón-cliente entre las partes involucradas en el intercambio de favores.

A medida que numerosas familias empezaron a enfrentar, de manera cada vez más frecuente, contextos de marginación y pobreza debido a las sucesivas crisis económicas, las redes de intercambio y solidaridad no desaparecieron, sino todo lo contrario: se intensificaron y surgieron como uno de los recursos estratégicos para asegurar la sobrevivencia de un número cada vez mayor de familias. Así, las redes familiares y amicales se presentaban como uno de los amortiguadores más eficaces para paliar las adversidades económicas y sus efectos negativos sobre las familias. Dicha participación estuvo mediatizada por el manejo y/o control de ciertos recursos. El acceso a determinados recursos significativos, particularmente el ingreso salarial, se convirtió en determinante a la hora de facilitar la participación y conservación de dichas redes, siendo éstas un recurso indispensable para el bienestar que lograban o no alcanzar las familias (G onzález de la Rocha, 1986; Estrada, 1996 y 1997; Sel by et al., 1994).

Incluso algunos investigadores (Adler Lomnitz, 1987; Adler Lomnitz y Pérez Lizaur, 1993; Chiarello, 1994) aseguran que

empresarios, profesionistas, empleados públicos y privados, así como a una parte importante de comerciantes. Es decir, una de las características distintivas y particulares de la población urbana afiliada a los movimientos de deudores es que son familias pertenecientes a los sectores medios (Ángeles, 1997). Esta situación se confirmó al momento de aplicarse la encuesta a esas 30 familias pertenecientes tanto a El Barzón como a la ACDB en sedes de los mismos movimientos en el Distrito Federal. 
ese tipo de respuestas tradicionales puestas en marcha por importantes sectores de la sociedad habían adquirido un carácter inmutable, permanente, inagotable y sin posibilidad de experimentar cambio alguno. De esa forma quedaban demostradas la superioridad y funcionalidad que habían adquirido las respuestas colectivas sobre aquellas que buscaban privilegiar las acciones de carácter individual.

Respecto a esas mismas bondades de las redes familiares, $\mathrm{F}$. Chiarello escribió lo siguiente:

D espués de todo, la familia y las redes sociales han representado siempre el amortiguador más eficaz de las adversidades económicas, por el simple hecho de que demuestran ser superiores al individuo aislado para resolver las situaciones más complicadas y en hacer virtud de la necesidad. Es bastante claro, de hecho que la familia y las redes sociales -representadas por los análisis convencionales como estructuras típicas de la sociedad "tradicional"- están muy lejos de ser eliminadas o incluso simplemente debilitadas por el desarrollo de la moderna economía de mercado (Chiarello, 1994: 183).

En una investigación posterior realizada por Larissa Adler Lomnitz y M arisol Pérez Lizaur (1993) entre un grupo de familias de la burguesía mexicana, se encontró la presencia de un modelo similar al que la misma Adler Lomnitz, años atrás, había descrito para los habitantes de la barriada de la Cerrada del Cóndor. Sobre las características del modelo familiar trigeneracional detectado entre las familias de la burguesía, estas investigadoras apuntaron que:

\begin{abstract}
$\mathrm{N}$ uestra tesis central es la preeminencia de la gran familia (es decir, la familia extensa de tres generaciones) en cuanto unidad significativa básica de la solidaridad en M éxico. Esta estructura se mantiene de manera activa con el tiempo. Además la familia -entendida culturalmente como unidad básica de solidaridad de la sociedad- es la gran familia trigeneracional. Esto significa que un individuo dado considera como su grupo básico, su unidad ritual, social y económica, no solamente a sus padres, hermanos, hijos (como en el caso de la familia elemental), sino a sus abuelos, tíos y primos. Esto, de partida, hace que cada individuo pertenezca a un grupo mayor de individuos entre quienes existe un sistema de expectativas, de derechos y de obligaciones de ayuda mutua (Adler Lomnitz y Pérez Lizaur, 1993: 28).
\end{abstract}

O tras investigaciones mostraron que, en situaciones de crisis, el modelo de las familias extensas era retomado como una de las estrategias para hacer frente a situaciones cada vez más frecuentes de desempleo y de falta de recursos económicos, y todo eso 
como resultado de los efectos de un modelo económico con el cual se imponía la escasez de empleo remunerado y el estancamiento de la economía, como algunos de sus elementos distintivos. Sin embargo, no hay que obviar que esa estrategia tenía un elevado costo entre las familias que terminaron por recurrir a dicha práctica. Esto debido a que posibilitaba, en lo inmediato, hacer frente a las situaciones de adversidad. Por ejemplo, se repartían los gastos de alimentación, se preparaban ollas comunes, se distribuía el trabajo doméstico, se delegaban funciones, y el control de los recursos normalmente terminaba por ser concentrado en un determinado miembro de la familia. Sin embargo, todo eso traía como consecuencia la generación de una infinidad de situaciones conflictivas entre los miembros de las familias que terminaban involucrándose en ese tipo de estrategias. N o obstante, las familias, con todo y esos conflictos, lograron restablecerse y tener cierto control sobre sus niveles de vida (Estrada, 1995).

Al igual que en los trabajos anteriores de Adler Lomnitz, $M$ argarita Estrada señaló que uno de los aspectos que facilitaban la organización de las familias en núcleos extensos se encontraba en la existencia de la reciprocidad entre los miembros de las familias. Esa reciprocidad se basa fundamentalmente en la capacidad de las familias involucradas en un proyecto de este tipo para llevar a cabo la redistribución de bienes, servicios y favores, lo que desembocaba principalmente en la conformación de un gasto múltiple o de un ingreso colectivo que se destinaba principalmente a solventar los gastos de la alimentación de la familia extensa. Lo anterior no quiere decir que no hubiera otra esfera de actividades en la cual se contribuyera de manera colectiva, sino que el éxito de esa organización doméstica se reflejaba principalmente en los arreglos económicos alcanzados para resolver aspectos relacionados con el ámbito de la alimentación y el cuidado de los hijos. Así pues, parecía que la flexibilidad de los proyectos y recursos familiares terminaría por mantenerse intacta por siempre, y al margen del impacto de una economía familiar, frecuentemente golpeada por la crisis, con efectos cada vez más perjudiciales para la organización familiar.

\section{Funcionamiento de las redes familiares en los años previos a la crisis de 1994-1995 entre las familias de sectores medios}

A partir de los datos que dejó la encuesta, en un primer momento, y de las entrevistas en profundidad, se pudo constatar el valor 
y la importancia que había llegado a adquirir para muchos individuos la participación en las redes conformadas entre los parientes, así como con personas ajenas al grupo familiar. La ayuda o el apoyo que de ellas habían obtenido en determinados momentos fue muy significativa, ya que permitió la resolución de una diversidad de situaciones. Por ejemplo, la obtención de la vivienda se logró, en algunos casos, por medio del préstamo de una cantidad para dar el enganche de la propiedad. En algunos casos se observó que otras familias habían logrado obtener una casa o un departamento en forma de regalo por parte de algún pariente cercano de la familia nuclear de uno de los cónyuges. O tras familias reportaron que fue la recomendación de algún pariente 0 amigo lo que permitió que en momentos difíciles algún miembro desempleado lograra obtener un nuevo trabajo remunerado.

Por ejemplo, el patrón predominante de residencia de las familias encuestadas y entrevistadas fue, y continuó siendo, aun después de la crisis, de tipo nuclear. Sin embargo, ese patrón de organización residencial no significó que las familias estuvieran haciendo referencia o que enfrentaran una condición de aislamiento social, o que por esa condición de residencia pudiera hablarse de plena autonomía de la familia. ${ }^{6}$

Podemos señalar que la activa participación de las familias dentro de las redes parentales y amicales estuvo determinada por el panorama de solvencia económica que caracterizó al entorno de las familias. La situación económica previa permitió el acceso a la educación en escuelas privadas, vacaciones, etc. Aunado a esos beneficios, la estabilidad en los ingresos económicos también hizo posible mantener relaciones de ayuda económica con determinados parientes. Dicha estabilidad permitió que se pudieran destinar semanal, quincenal o mensualmente, importantes cantidades de dinero a parientes cercanos (padres, hermanos y ocasionalmente tíos y primos). Esos recursos eran utilizados para cubrir gastos de alimentación, educación y vestido, 0 servían simplemente como un mecanismo de ahorro económico para sus destinatarios. En otros casos, la ayuda económica era destinada al pago de las colegiaturas de algún familiar cercano.

${ }^{6}$ Por ejemplo, Sussman y Burchinal (1980), quienes llevaron a cabo investigaciones entre familias de los sectores medios estadounidenses durante los años sesenta, cuestionaron y refutaron la idea del aparente aislamiento social de esas familias. Para sustentar su argumento, mostraron la importancia y el grado de participación de esas familias nucleares en numerosas redes de solidaridad y ayuda mutua, en especial de los padres, aun mucho después de que éstas se habían formado. 
También hubo casos en que algún familiar se trasladó a la ciudad de M éxico para vivir en la casa de algún familiar cercano, siendo este último quien se hacía cargo de absorber gran parte de los gastos del o de los parientes adoptados. En otros casos, la familia que adoptaba a algún familiar le ayudaba otorgándole únicamente un espacio dentro de la vivienda, mientras que el resto de los gastos los seguían cubriendo los padres de éste, sus hermanos 0 algún otro pariente cercano. También la mayoría de las familias siguió teniendo una activa participación en festividades de carácter ritual y festivo como bodas, xv años, bautizos y confirmaciones tanto dentro como y fuera del ámbito familiar. Recordemos que tanto la promoción como la participación en dichas festividades se asumen como una oportunidad para poner en marcha la ostentación, el poder, la solidaridad, pero también como una oportunidad de discriminar a los que no son parte del núcleo o que no tienen la condición de ser recíprocos.

Reitero: un aspecto fundamental fue que la participación de las familias en esos procesos de intercambio y redistribución de bienes resultó funcional en la medida en que, como lo señaló Enzo M ingione (1994), las familias eran capaces de contar con ingresos económicos suficientes que las respaldaran en su involucramiento en dichas redes de intercambio. Por ejemplo, en una de las entrevistas un informante describió de la siguiente manera el uso y el destino de una parte de sus ingresos en años previos a la crisis:

Pues yo los destinaba pues a cambiar el auto, a seguir viajando. Yo tengo una hermana que vive en Guanajuato y económicamente la podía ayudar, ¿verdad? En eso lo destinaba yo, y en el poder ahorrar algo. M i hermano tuvo problemas con su negocio en León, un negocio de tornos y su niña se tuvo que venir a vivir conmigo. Entonces prácticamente yo tuve que apoyarlos a ellos (testimonio de un miembro de una familia deudora).

En otros testimonios, los argumentos presentados por los informantes secundan lo señalado por el anterior, cuando indicaban que, por ejemplo, una parte de su ingreso salarial era destinado para: "... ayudar a mis padres en sus gastos. En ocasiones también le echaba la mano a alguno de mis hermanos, y más frecuentemente a los hijos" (testimonio de familia deudora).

Un informante comentó que, mientras el jefe de familia contó con un empleo y no enfrentaron el problema de la cartera vencida, él contribuyó durante muchos años a solventar los gastos de 
sus padres, quienes además recibían una pensión, la cual era insuficiente para cubrir el monto de sus necesidades.

\section{Después de la crisis: efectos de la crisis en la participación en las redes de solidaridad y reciprocidad}

La crisis económica de 1994 se tradujo en la experiencia del desempleo entre al guno de los miembros de la familia (véase cuadro 4) y, en consecuencia, en el deterioro de sus ingresos. Esa situación derivó en que en algunas de las familias deudoras, y también en algunas no deudoras, pero principalmente en las primeras, se tuviera que recortar de manera temporal la ayuda económica que se destinaba a la manutención de otros familiares.

La falta o la escasez del salario de uno o más miembros de la familia se manifestó también en la disminución de las frecuentes visitas que se hacían a otros parientes y amigos. En otros casos se dieron situaciones en las que se tuvo que dejar de dar hospedaje a algunos parientes. El siguiente caso ejemplifica esa experiencia:

Actualmente que ya no hay empleo seguro, tampoco hay aguinaldo, no hay comisiones, no hay ya nada de lo que tenía antes. Ya lo que sale del trabajo apenas sirve para irla pasando. Apenas, la semana pasada, tuvimos que regresar a una sobrina a su casa con su mamá, es hija de la hermana de mi esposa que vivía con nosotros, ya que ya no alcanzaba para seguirla teniendo en la casa. Aquí se le vestía, calzaba y se le daba escuela, pero llegó el momento en que ya no se le pudo solventar nada, y tuvimos que regresársela a su mamá (testimonio de familia deudora).

\section{Cuadro 4 \\ Distribución de las familias en las cuales al menos uno de sus miembros perdió el empleo}

\begin{tabular}{lcr}
\hline Familias encuestadas & $\begin{array}{c}\text { Cantidad de familias } \\
\text { donde al menos un } \\
\text { miembro perdió el empleo }\end{array}$ & Porcentajes \\
\hline Deudoras (30) & 17 & $57 \%$ \\
Villa Panamericana (31) & 7 & $22 \%$ \\
Universidad pública (34) & 7 & $20 \%$ \\
Universidad privada (15) & 3 & $20 \%$ \\
Total: $110(100 \%)$ & 34 & Total 31\% \\
\hline
\end{tabular}

Fuente: Encuesta aplicada a las familias durante el trabajo de campo. 
Al momento en que la crisis irrumpió en el panorama de las familias, éstas empezaron a destinar la mayor parte de sus ingresos para satisfacer solamente las necesidades inmediatas y más apremiantes de los miembros de la propia familia nuclear, principalmente en rubros como la educación, la alimentación y el pago de algunos servicios de la casa como agua, electricidad, gas y teléfono.

Varias familias pasaron de ser de distribuidoras de recursos económicos y favores a otras redes familiares, a ser únicamente receptoras de importantes beneficios económicos y diversos apoyos morales por parte de sus redes familiares. No obstante, es importante señalar que esas familias no terminaron por enfrentarse a una situación de aislamiento total, puesto que siguieron formando parte de las redes familiares. Simplemente sucedió que algunas ya no tenían la capacidad de mantener relaciones de intercambio económico con el resto de los grupos con los cuales anteriormente interactuaban. Eso se debió fundamentalmente a que los ingresos que les habían permitido durante años el mantenimiento de relaciones entre iguales, se habían reducido de manera significativa. En esos casos, su papel en la red familiar y fuera de ella se limitó únicamente a recibir ayuda económica y otro tipo de favores. Pero ellas dejaron de hacer aportaciones económicas. El principal aporte que ahora ofrecían esas familias era, por ejemplo, el cuidado de los enfermos, la atención a niños y ancianos, el cuidado de madres embarazadas; es decir, situaciones en donde no se ponían en circulación recursos económicos.

Cabe destacar que el establecimiento de ese tipo de arreglos no estuvo exento de situaciones de crisis y conflictos en la red de parientes. Una informante reconoció el valor y la importancia de los apoyos de toda índole, que ella y su familia habían recibido de sus hermanas y su madre. Uno de ellos consistió en que ella y su familia pudieron ocupar dos cuartos en la casa de su mamá. Sin embargo, la misma informante señaló que el costo de esa ayuda se había traducido en un mayor involucramiento de sus hermanas y su madre en muchos ámbitos de su vida privada: "Ahora están al pendiente de que si el esposo no llevaba dinero, que si el esposo llegaba borracho, que si la engañaba".

N o obstante, algunas familias deudoras lograron conservar la capacidad de ahorro económico. Pero se consideró que tales recursos económicos, lejos de solventar o resolver problemas de otros miembros de las familias de los cónyuges, tendrían prime- 
ro que destinarse a la resolución de los problemas que se habían generado por el problema de la cartera vencida, y que en algunos casos llegó a poner en peligro la posesión del principal patrimonio familiar: la vivienda. Ello provocó que se experimentaran situaciones como la siguiente:

Con mis hermanos tengo una muy buena relación aunque sí siento que me he dejado de involucrar en su problemática porque ando tan metida en la mía, que sí me ha aislado. M ira, por ejemplo, si mi hermana o alguien tiene algún problema económico, ya no le entro ¿no? A lo mejor sí, y creo que en algún momento difícil de alguno de ellos le entraría de corazón, pero mientras no vea así una situación crítica no lo hago [... ] mientras no se presente al guna situación crítica, no me meto, porque eso implicaría sacar el bienestar económico del banco, y yo se que ese dinero del banco lo estoy esperando para la búsqueda de una solución a mi problema de la deuda (testimonio de familia deudora).

Un informante de una familia deudora resumió, en los siguientes términos, el tipo de relación que mantenía su familia con algunos parientes y amigos:

Debe de ser vergonzoso [refiriéndose a la situación de su esposa] el que sus amistades y sus conocidos sepan que tiene que vender, vender esto y lo otro, lo cual a ella, en el fondo, puede afectarle desde una cierta pena. Pues no creo que a nadie le guste mostrar que está en la vil mendicidad, y sin embargo digo mendicidad porque se ha dado el caso de algunas amigas que le llevan y le regalan despensas y le regal an cosas de ese tipo, no le dan dinero pero le dan arroz, fríjol, latas, etc. En el sentido de tener para ella eso sí es penoso pedirle a su mamá cada mes que la apoye económicamente para ir sorteando los gastos de la casa o a sus hermanos. Porque sí siente en el fondo que ellos sí se lo dan y sí la apoyan, aun cuando no tienen mucha capacidad económica ciertamente. Pero en el fondo, siempre se queda la cosa de que esto le correspondería a su marido, no a nosotros (testimonio de familia deudora).

Las experiencias de las familias deudoras mostraron que las redes se han consolidado como uno de los principales recursos para el sostenimiento y satisfacción de muchas necesidades de los miembros del hogar. Un ejemplo de esa situación es el de una familia que actualmente vive en un pequeño departamento que forma parte de la casa de la madre de la esposa, lo cual implica un ahorro significativo por el hecho de no tener que pagar renta. También reciben ayuda de la red familiar principalmente para los hijos, lo que se ha traducido en la compra de ropa, calzado y útiles escolares por parte de tíos o de la abuela materna. En otras ocasiones les han prestado dinero para resolver alguna situación imprevista: 
Ya no podíamos hacer gastos en ropa, que afortunadamente por parte de mi esposo, sus hermanas compran para mis hijos. Yo te voy a decir que en este tiempo que llevamos, ellas les han comprado su ropa, ellas los calzan, los visten. 0 sea, yo les doy también a ellas las gracias (testimonio de familia deudora).

También hay que señalar que encontramos la situación contraria, en donde una familia no deudora había experimentado situaciones de aislamiento. Fue una experiencia propiciada por las condiciones actuales de la familia, en donde el ingreso del jefe de familia se vio muy reducido debido a situaciones particulares de su trabajo. Por ello, la familia no pudo en adelante continuar sosteniendo relaciones de reciprocidad entre el grupo de amigos más cercanos. Incluso terminarían por no volver a solicitar ayuda entre los amigos, y mucho menos entre los parientes; según el informante, para no mostrar ante el resto de los amigos y la familia, la situación de escasez de recursos y todas las privaciones a las que estaban sometidos. El informante señaló lo siguiente:

\begin{abstract}
Yo siento como que el grupo de nosotros de amistades es muy bueno, y que sí pudiéramos pedir prestado. Pero mi marido no quiere, como que prefiere hacerse bolas él solo y ver cómo le hace. Y bueno, yo estoy de acuerdo porque ahora sí, hablando de prestigio, es ¿cómo decirlo? como que te desdoras (testimonio de familia de universidad pública).
\end{abstract}

En esa misma familia se aceptó que una de las repercusiones inmediatas fue haber dejado de participar con el grupo de amigos y de organizar reuniones en casa:

\begin{abstract}
Anteriormente todos los fines de semana había 10 o 15 amistades en casa. Ahora ya no lo podemos hacer, y sí, como que te sientes aislado. Tenemos otras amistades, que bueno son con los que nos vemos y que nos invitan a sus casas, y la verdad que son espléndidos, y el asunto de la reciprocidad pues sí pesa. Cómo les voy a decir: "Pasen", y les voy a dar unos pinches cacahuates, cuando ellos te sacan de lo mejor: vinos importados y demás (testimonio de familia de universidad pública).
\end{abstract}

La situación de insolvencia e incapacidad económica que enfrentaría la mayoría de las familias de deudores, y también algunas de las no deudoras, provocó que la participación en redes de intercambio y de ayuda tuviera que verse relajada o temporalmente suspendida. Así pues, la incapacidad de las propias familias de asegurarse los suficientes recursos que les permitieran seguir participando en esos mecanismos de redistribución de re- 
cursos que son las redes, terminó por conducir a un fenómeno de aislamiento o privatización de la vida. En ese mismo contexto, el uso y destino que empezaron a tener los ingresos de la familia se enfocaron en satisfacer principalmente las necesidades de los miembros de la familia nuclear. Eso en perjuicio del resto de los miembros que anteriormente se veían beneficiados de la distribución de recursos.

Por ejemplo, para las familias deudoras, no disponer de suficientes recursos económicos no fue el único impedimento para seguir siendo parte de los sistemas de intercambio. El problema de la deuda no sólo representó un deterioro en las relaciones familiares, sino que también repercutió en la pérdida del reconocimiento familiar, la confianza y la honorabilidad, y en otros casos se tuvieron que enfrentar actitudes de rechazo, incluso por parte de parientes, amigos cercanos, vecinos o compañeros de trabajo. Así, para algunos deudores, la deuda con el banco contribuyó a que se les empezara a rechazar; significó que se les acusara de ser ellos los causantes de los problemas financieros que experimentaba el país. M uchos empezaron a vivir con un estigma: "Ios malos gobernantes y los malos banqueros nos han señalado como irresponsables, como personas insolventes, tanto moral como económicamente. Eso no lo aceptamos porque eso no es cierto y revertimos las acusaciones" (testimonio de familia deudora).

0 tro informante relató, en los siguientes términos, el impacto que había causado entre sus anteriores socios inversionistas el hecho de que él formara parte de la cartera vencida:

\begin{abstract}
Para todos ellos, yo estaba considerado como una persona digna de apoyo y confianza y como sujeto de crédito. Ahora ya no soy sujeto de crédito, ni digno de confianza. Ahora estoy en cartera vencida, en la lista negra, considerado como ladrón y estafador; enfrentando, junto con mi familia, presiones, amenazas, demandas y embargos provenientes de bancos, gobierno, agiotistas y proveedores (testimonio de familia deudora).
\end{abstract}

M uchas fueron las familias que tuvieron que enfrentar la agresión y la persecución por parte de los banqueros. En muchos casos se empezó a vivir con miedo y con la vergüenza de tener que deberle dinero al banco. Algunos, incluso, no buscaron apoyo y solidaridad dentro de los propios círculos familiares más cercanos. H ubo casos en los que se trataba, por todos los medios, de que los problemas no trascendieran del ámbito de la familia nuclear. M ientras tanto, para otros el apoyo y el respaldo que encontraron, vinieron fundamentalmente de fuera de sus 
familias: "ahora tengo que vivir en una situación de anonimato. El banco nos ha hecho creer que somos de lo peor, porque no podemos pagar lo que ellos nos cobran. Y bueno, yo siento mucha vergüenza por no poder pagar. M i nombre no se lo doy a nadie" (testimonio de familia deudora).

Así como las familias deudoras de nuestra muestra evidenciaron ser las más vulnerables a los efectos de la crisis, en comparación con el resto de las familias estudiadas, hay que destacar en este grupo de familias el surgimiento de una serie de nuevas experiencias que se vinieron a integrar al conjunto de las maltrechas relaciones familiares en su vida cotidiana. Esas experiencias se dieron en el momento en el que esas familias decidieron ingresar a una organización que agrupaba a personas que compartían la misma problemática: es decir, la cartera vencida. Tener que enfrentarse a los bancos provocó que tuvieran que sufrir con las demandas de los servicios jurídicos de éstos. Así, las familias deudoras se vieron en la necesidad de aprender a defender su patrimonio desde una posición jurídica, de asistir a tribunales y de manejar el discurso y el lenguaje de las leyes. Como ellos decían: "no alcanza para el abogado y hay que ir personalmente a levantar demandas o realizar cualquier trámite legal". La compañía y la solidaridad que se prestaban entre ellos se manifestaron al momento de compartir, ayudar y ofrecer asesoría jurídica a aquellos que, de un momento a otro, no tuvieron la posibilidad de seguir cubriendo los depósitos mensuales, además de los honorarios de un abogado.

El análisis y el seguimiento constante de la vida política y el conocimiento de la evolución de los principales indicadores de la vida económica del país fueron temas y situaciones que se integraron de golpe a la vida y al discurso cotidiano de las familias. Era precisamente esa información la que se transmitía en las reuniones semanales a las que acudían los deudores. En las reuniones se discutía y analizaba el rumbo del país, y los deudores se ponían al tanto de las negociaciones con los banqueros, y las declaraciones y acciones de funcionarios públicos. Se socializaban también las experiencias que las familias habían tenido con los bancos, los agiotistas y los abogados de éstos. De igual manera, tanto los logros como los fracasos se convirtieron en ejemplo para el resto del grupo, y éstas eran experiencias de las que todos los involucrados intentaban sacar al gún beneficio. La solidaridad entre las familias deudoras se manifestaba cuando acudían a los tribunales, a las casas o negocios para impedir embargos o des- 
alojos de la vivienda, así como los remates de las propiedades de los demás deudores.

También entre los integrantes de las asociaciones de deudores a las que tuve oportunidad de asistir resultó común ver que se ofrecían productos y servicios que eran elaborados y desarrollados por ellos mismos. Igualmente, si algún miembro se encontraba en una situación económicamente difícil, se realizaban colectas, rifas o donaciones con tal de manifestarle el apoyo y la solidaridad del grupo. La solidaridad se manifestaba inicialmente con el simple hecho de aceptar a los demás, aquellos que se encontraban en la misma situación, de perder la vergüenza y compartir su experiencia con otras personas, y que en un primer momento resultaban ser totalmente desconocidas. Para los deudores y sus familias fue importante darse cuenta de que sus problemas de cartera vencida no eran algo que enfrentaran únicamente ellos o unos cuantos, sino que era un problema generalizado en la mayor parte de las familias del país. Así se hizo patente la solidaridad entre los deudores.

Esas nuevas redes de ayuda y solidaridad que se construyeron al interior de los grupos y de las organizaciones de deudores vinieron a ser de gran importancia para las familias, ya que terminaron por convertirse, para la gran mayoría, en uno de los últimos recursos a los cuales recurrieron cuando sus redes familiares y amicales empezaron a mostrar, como en algunos de los casos que aquí se han presentado, sus límites.

\section{Funcionamiento de las redes de solidaridad y reciprocidad entre las familias con escasa afectación por la crisis}

Sin embargo, la vulnerabilidad mostrada por algunas de las familias en relación con su participación dentro de las redes de intercambio familiar, no se presentó en todas las familias consideradas en nuestra investigación. Por tanto, las experiencias de relajamiento en la participación dentro de las redes fue un proceso que no se pudo generalizar para la totalidad de los casos aquí estudiados. Es decir, a pesar de los vaivenes experimentados por la economía nacional, un reducido grupo de familias logró mejorar su situación laboral y salarial. Así, en pleno contexto de crisis y de reacomodos de los sectores productivos ante una nueva estrategia de acumulación, también fue posible encontrar familias en las que algunos de sus miembros, como profesionales, lograron conservar su empleo e incluso mejorar sus 
condiciones salariales en las empresas en donde trabajaban. Aquí se trata de un grupo de familias en las que uno o ambos cónyuges se encontraban laborando en alguna de las empresas que habían recibido los beneficios de la apertura comercial e incluso se habían visto beneficiadas a partir de la devaluación del peso frente al dólar norteamericano, debido a que se dedicaban fundamentalmente a la exportación de gran parte de su producción. La calidad de vida de los miembros de esas familias a raíz de la crisis de 1994-1995 no se vio realmente afectada. Los hijos siguieron estudiando en escuelas privadas y siguieron saliendo de vacaciones dentro y fuera del país. Es decir, la vida cotidiana siguió siendo la misma antes y después de la crisis. R eitero: incluso en algunos casos los ingresos de los cónyuges se vieron incrementados notablemente.

Esa situación sirvió como impulso para que dichas familias siguieran manteniendo una participación activa dentro de las redes familiares y amicales. Para esas familias, las redes tuvieron y continuaron teniendo un valor estratégico. Sobre este hecho, un informante señaló lo siguiente:

\footnotetext{
Bueno, el futuro para mis hijas lo veo muy bien. Para esto pues se combinan dos aspectos: el que ellas tengan un buen currículum, y otro aspecto importante para lograr colocarte lo tienen por el lado de las amistades y por el lado de las relaciones. Y bueno, nosotros contamos con amistades y relaciones, y a ellas recurrimos para determinados asuntos. Pero no estamos esperanzados únicamente a ellos. Es decir, podemos recurrir a ellos para un asunto, pero es en un sentido de reciprocidad, de iguales: yo te ayudo, pero estamos en un mismo plano. $\mathrm{M}$ i hija trabaja actualmente en $\mathrm{H}$ acienda, en el área de recaudación internacional. Y bueno, se logró colocar ahí porque tiene una buena preparación, y porque un conocido de la familia la ayudó (testimonio de familia de universidad pública).
}

Las redes para esa familia se valoraban como un recurso altamente significativo, y se consideraban como una opción real que permitiría la consecución de proyectos a mediano y largo plazos para sus miembros. Incluso podemos señalar que el bienestar del cual hoy en día gozan esas familias estuvo sustentado en una importante integración a redes que se construyeron, en un primer momento, en un plano familiar, y que posteriormente se extendieron hasta el ámbito de grupos de profesionistas. Lo significativo de muchos de esos profesionistas es que eran miembros de gremios en donde se compartía y transmitía información que se generaba dentro esos grupos y en los niveles más altos del 
poder económico y político. Dicha información resultaba ser fundamental para la planeación y consecución de proyectos profesionales, y terminó por ejercer una innegable influencia en importantes decisiones, en el momento de iniciarse o cerrarse una transacción o un negocio. Además de la información laboral que se intercambia entre ellos, la información de carácter económico resultó ser de gran importancia. Un caso reseñado nos ayuda a entender el valor que puede llegar a adquirir el hecho de colocarse dentro de esas redes de intercambio:

En el grupo de amigos en el que se mueve mi marido, sí se apuntalan unos a otros. Eso sí lo he visto porque sí se da, porque ahorita me ayudó tal; o llegan con mi marido y le dicen: "¿Tienes posibilidades? Ayúdame ahorita y yo te recupero en esto". Se están haciendo muchos grupos de ayuda. Han resurgido también grupos de préstamo por grupo de profesionistas que están agremiados. Ahorita hay muchos profesionistas que están colegiados, y en eso se ayudan mucho porque se consiguen cuotas, se consiguen préstamos especiales, con otro tipo de intereses, a otros plazos y se ayudan mucho. Se consiguen muchas cosas entre ellos, por lo agremiados que están (testimonio de familia de universidad pública).

De igual forma, el hecho de haberse mantenido la participación de esas familias en redes familiares, amicales y de trabajo, permitió perpetuar la participación en numerosas ceremonias de carácter estrictamente familiar, y en otras que trascienden los límites estrictos de la parentela. Eso se observó en la tradición que mantienen muchas familias de reunirse de manera constante. Dichas reuniones resultan ser un espacio privilegiado, pues allí se comparte y transmite información relevante para todos los presentes. Algunos miembros de las familias aparecen como los concentradores de la información, y en torno a esas personas se reúnen las demás, contribuyendo así a la conformación de liderazgos y lealtades internas. Además, dichas reuniones sirven como una oportunidad para continuar reforzando el ideal de la continuidad de la gran familia solidaria. En ellas se transmite información sobre la situación y las problemáticas que enfrentan los parientes. Y, lo más importante, allí mismo se construyen, se planean y se toman decisiones con las que se busca resolver la situación de aquellos miembros de la parentela que enfrentan alguna necesidad o algún problema en particular. Además, sirven para que entre los miembros se transmitan valores y, lo más significativo: información valiosa para el bienestar de las familias. 
El relato de un informante muestra la importancia y la manera en que se desarrollan esas prácticas sociales y rituales:

Todos llegamos a casa de mi mamá. Llegamos: "O ye, ¿cómo están los hermanos?", y ya platica de todo. Entonces, como que nos enteramos de lo que sucede. Nosotros sí vivimos muy en familia, y todo lo que pasa entre hermanos, lo sacamos, y si alguno está con problemas económicos o de otra índole, entre todos sacamos adelante la carreta del que esté en problemas. N os vemos muchísimo, mis hermanos y yo sí nos vemos muchísimo. Andamos mucho juntos y nos hablamos mucho y varios no viven en el Distrito Federal, pero a través de mi mamá estamos siempre en contacto (testimonio de familia de universidad pública).

Lo significativo del testimonio anterior no es sólo si se participa o no, o si se sigue conservando la tradición de la reunión; el significado más profundo de dichas prácticas está en el hecho de que en esas familias, la solidaridad se continuará haciendo presente en ese tipo de rituales. Las reuniones se conciben como un espacio de verdadera solidaridad entre los miembros del grupo. Así, la permanencia de esos rituales entre las familias estudiadas contribuyó a que se asegurara la permanencia del grupo y a la vez a que se reafirmaran los vínculos de parentesco. Parte del testimonio anterior presenta una situación muy semejante a lo reseñado por Adler Lomnitz y Pérez Lizaur (1993) cuando hacen referencia a la importancia que tuvo la participación en ese tipo de rituales familiares para familias de la clase empresarial de la ciudad.

Las autoras destacan los siguientes puntos, en torno a la importancia y a la permanencia de esos acontecimientos rituales, comentando que:

\begin{abstract}
Ser Gómez significa entre otras cosas participar en un complejo sistema eslabonado de acciones simbólicas que equivalen a una forma de vida [... ] cada forma transmite un mensaje que se relaciona con el estatus, la cercanía personal, la competencia y el conflicto [... ] es un espacio de ostentación y poder, aspiración al liderazgo, lealtad y rencor, solidaridad y discriminación [... ] la participación en estos rituales redunda en mucha información (Adler Lomnitz y Pérez Lizaur, 1993: 177).
\end{abstract}

Para esas familias, contar con esos grupos de ayuda y de respaldo resultó ser fundamental. Ello, independientemente de la etapa del ciclo doméstico en la cual se encontraban, ya que esas redes adquieren un peso decisivo incluso desde el momento mismo en que los jóvenes inician su vida matrimonial. M uchos de ellos se casan, y cuando lo hacen resulta que ya tienen la casa 
'Ievantada' y con todos los muebles necesarios. En algunos casos tienen también la posibilidad de contar con casa propia gracias a la acción de las redes familiares.

De esta forma, contar con una estabilidad económica a partir de la participación en empresas y sectores laborales exitosos, aun en los mismos contextos de crisis económica, fue un factor fundamental para participar activamente en un conjunto de actividades que le permitió a ese reducido sector de familias mantener y reproducir patrones de conducta. Ello, a su vez, les permitió seguir diferenciándose de aquellos grupos familiares que, debido a circunstancias principalmente de orden económico, fueron excluidos de los procesos de intercambio y, como resultado, fueron también excluidos de las redes familiares y sociales.

También parte de las redes familiares permitió, entre otros beneficios, que los jóvenes lograran insertarse en diversas redes de tipo económico, laboral, educativo y simbólico, constituyéndose dichas redes en importantes medios para la construcción de patrones de diferenciación social y de identidad, en torno a los miembros de sus grupos de pertenencia. Para dos amas de casa, el futuro profesional de sus hijos se consideraba en los siguientes términos:

Cuenta mucho el currículum ante todos los profesores y ante el trabajo, y que son las fuentes y los hacen manejarse en estas universidades como líderes más que técnicos. Y no van a ser empleados. $\mathrm{No}$, van con otra mentalidad: ustedes van a ser los líderes que van a aprender a dirigir, y así con esa mentalidad funcionan, así nos está tocando. No sé si es buena o sea mala, pero esa es una realidad muy palpable del país. $\mathrm{N}$ o, a ellos ni se les ocurre ser empleados: van a dirigir. Si ellos quieren llegar y dónde me voy a instalar y tienen la capacidad, tienen, porque así les dio la vida, otro tipo de oportunidades. H ay quien las aprovecha y hay quien no (testimonio de familia de universidad pública).

Es decir, en la medida que siguieron formando parte de las estrategias de ayuda e intercambio, esas familias pudieron mantenerse en una situación de iguales con su contraparte. De tal forma que están en disposición de solicitar ayuda o el favor de algún tercero, pero a su vez ellas también están en posibilidad de convertirse en apoyo de otras familias. Para esas familias, las redes siguieron operando de forma completa. Es decir, se siguen redistribuyendo favores y recursos. Por tanto, es posible concluir que en los últimos casos descritos siguió teniendo fuerza y funcionalidad el modelo de la gran familia trigeneracional prefigurado por Adler Lomnitz y Pérez Lizaur (1993), en la medida 
en que esas familias pudieron seguir manteniendo asegurada la entrada de un ingreso económico lo suficientemente alto como para seguir solventando los altos costos económicos que implica la participación en los rituales de intercambio y de reciprocidad.

\section{Conclusiones}

Asegurar la participación dentro de las redes familiares implica estar en condiciones de colaborar con fuertes inversiones económicas (M ingione, 1994). Sin embargo, ante el panorama económico desfavorable de estos últimos años se volvió sumamente difícil para la mayoría de las familias incluidas en nuestro estudio mantener su participación en amplias redes de intercambio, en festividades de carácter ritual y en otros mecanismos de reciprocidad. Es decir, en contextos que se han caracterizado por una incapacidad para proveer a las familias con empleos asalariados, se vuelve cada vez más difícil seguir desarrollando una actitud de solidaridad para compartir bienes cada vez más escasos en nuestra sociedad como lo son el empleo y el ingreso salarial.

En investigaciones realizadas entre los sectores populares (González de la Rocha, 1986) se habían mostrado como casos aislados a los hogares en los que no existía la participación en las redes de intercambio. Esas familias resultaban ser las más pobres. Sin embargo, lo significativo de rescatar esa experiencia para el contexto actual es destacar cómo en la década de los ochenta esos casos eran presentados como excepcionales entre las familias pobres, mientras una década más tarde empezaron a dejar de ser casos aislados para convertirse en uno de los efectos de mayor impacto en la vida cotidiana de las familias de los sectores medios. Escenarios que parecían aislados y poco frecuentes, en la actualidad se han vuelto una experiencia cotidiana para un grupo de familias cada vez más amplio de la sociedad mexicana. Esto último queda reflejado en el hecho de que las experiencias de aislamiento y deterioro del tejido social que aquí hemos presentado, coinciden con otras experiencias que han sido detectadas por otros investigadores entre familias de distintos sectores económicos en diversas entidades del país (González de la Rocha, 1999; González de la Rocha y Villagómez, 2004). La situación de inestabilidad económica y laboral que enfrentaron una parte significativa de las familias aquí estudiadas permitió comprender que al gunos de los gastos más imprescindibles eran destinados a satisfacer las necesidades del grupo familiar inmediato. 
Es decir, los escasos ingresos económicos se destinaban a satisfacer las demandas de los miembros de la familia nuclear y, por lo tanto, esas formas de solidaridad intrafamiliar que durante muchos años se habían mostrado como inagotables, empezaron a dar muestra de límites reales para poder seguir funcionando. Tal situación generó que muchas familias entrevistadas manejaran sus ingresos únicamente para hacer frente a las demandas y necesidades del ámbito familiar nuclear. Lo significativo de ese fenómeno es que se extendió a un número mayor de familias. Además, todo esto hace preocupante el panorama, pues implica que cada vez se hace más difícil asegurar la permanencia de uno de los recursos (las redes de intercambio y reciprocidad familiar) que ha estado presente durante muchos años para mejorar las condiciones de vida de las familias. Lo anterior llevó a que las familias replegaran sus proyectos a un ámbito exclusivamente nuclear. N o obstante, es importante destacar que para las familias aquí estudiadas no se puede plantear una total desarticulación de la solidaridad que existe, o que culturalmente se había venido construyendo, al interior de las organizaciones familiares. Lo que sí hay que subrayar es la posibilidad para muchas familias de enfrentar una ruptura temporal, o tal vez definitiva, de la capacidad de seguir sosteniendo las relaciones de reciprocidad.

M arcel M auss (1979), en su clásico ensayo del don, señaló que quedar fuera de esos procesos redistributivos equivalía a sufrir, por parte de los afectados, una pérdida de status. Es decir, participar en el intercambio implica un dominio de estratificación y jerarquías. En los procesos de intercambio se reúnen como iguales sólo los que están en condiciones de solventar los gastos que implica el formar parte de la red. De igual manera, se termina por excluir a todos aquellos que no son lo suficientemente solventes para mantener el nivel del intercambio.

Para muchas familias, el apoyo moral logró mantenerse, y es posible que en situaciones como las actuales se incremente; pero las relaciones que tienen que ver con movilización de recursos económicos se vieron transformadas radicalmente. No estar en condiciones económicas de establecer relaciones de intercambio recíproco no quiere decir que esas familias experimenten una situación de completo aislamiento social, pero aumentó lo que podría definirse como la 'nuclearización' de la vida familiar. En algunas familias, ese proceso tendió a adquirir mayor importancia para la producción y concentración de recursos que en aqueIlas familias que pueden mantener la participación con el resto 
de las redes familiares y amicales. Ese hecho mostró que las experiencias de la polarización en el ámbito económico a partir de la reestructuración del modelo de acumulación económica han conducido también a una polaridad en las relaciones sociales. Es decir, así como hubo experiencias en las que se hizo evidente el límite de las redes de participación solidaria, hay otras en las que siguió conservándose intacta la participación en las redes de intercambio. Por lo tanto, en la medida que al gunas familias logren mantener el acceso a la posesión y control de los recursos económicos, estarán en condiciones de seguir participando en relaciones cotidianas de la familia y en rituales, que tienen la ventaja de transformarse y ser utilizados como un importante recurso familiar en situaciones de deterioro de las condiciones de vida. Es decir, los datos y casos aquí expuestos muestran cómo en determinadas circunstancias las redes familiares pueden seguir siendo igual de eficientes e igual o más extensas.

Al inicio del presente capítulo señalé la flexibilidad y la importante capacidad de respuesta que se gestaron dentro de las familias al momento de enfrentarse situaciones adversas. Q uiero terminar este trabajo haciendo referencia a ese potencial de respuesta desarrollado entre las familias de la muestra, pero principalmente entre el grupo de las familias deudoras. Aquí vale la pena detenernos un poco y destacar cómo algunas modalidadesestrategias para desarrollar mecanismos de solidaridad y reciprocidad se debilitaron, y cómo a la par de ese proceso terminaron por gestarse otras redes más. EI hecho de que muchas familias se involucraran en movimientos de deudores, no sólo les brindó la oportunidad de defender su patrimonio mediante la vía jurídica, sino que también posibilitó y dio la oportunidad de que se accediera a la conformación de importantes redes de apoyo y de solidaridad entre la mayoría de los participantes. En un sentido, se accedió a esa nueva oportunidad de construir otras formas de socialización, de generar nuevos vínculos sociales, de acceder a nuevas formas de intercambio que vinieron a suplir la carencia de vínculos y apoyos que muchas familias habían perdido al interior de las propias redes familiares. Por lo tanto, el potencial de las familias para generar nuevas redes de apoyo trascendió los límites establecidos por las relaciones propias del ámbito del parentesco o del ámbito residencial. Esas nuevas redes, que se construyeron desde el interior de los movimientos sociales, brindaron a la mayoría de sus miembros la posibilidad de obtener beneficios directos para las familias. Desde el simple hecho de 
conocer las reglas o los pasos para llevar a cabo un trámite jurídico, hasta acciones concretas que permitieron conservar el patrimonio familiar.

Finalmente señalo que no hay que rastrear los efectos de las crisis exclusivamente en el deterioro que pudieron haber experimentado 0 no los indicadores económicos o las transformaciones en la calidad de vida. También hay que pensar en el impacto de las crisis económicas, y cómo muchas de sus secuelas vinieron a socavar y a alterar también de forma significativa el mundo de las relaciones intra y extrafamiliares, las cuales, como aquí se ha reiterado, son un recurso sumamente valioso en las expectativas de las familias para lograr, o no, a mediano y a largo plazos, una mejoría en la calidad de vida.

\section{Bibliografía}

Adler Lomnitz, Larissa (1987), Cómo sobreviven Ios marginados, Siglo xxı Editores, M éxico.

y M arisol Pérez Lizaur (1993), Una familia de la elite mexicana. Parentesco, clase y cultura. 1820-1980, Alianza Editorial, M éxico.

Alonso, Jorge y Rubén Aguilar (1980), Lucha urbana y acumulación de capital, Centro de Investigaciones Superiores del INAH, Ediciones de la Casa Chata, M éxico.

Ángeles, Tatiana (1997), “El Barzón ante la coyuntura electoral de 1997", en Jorge Fuentes M orua, Enrique García M árquez, Alberto Arroyo Picard y Cenobio Briones Sánchez (coords.), Significado y posibilidades de la coyuntura político-el ectoral , Universidad Autónoma M etropolitana-Iztapalapa, M éxico, pp. 59-61.

Arizpe, Lourdes (1973), Parentesco y economía en una sociedad náhua, Instituto $\mathrm{N}$ acional Indigenista-Secretaría de Educación Pública, M éxico.

(1978), Migración, etnicismo y cambio económico, El Colegio de M éxico, M éxico. 
Bazán, Lucía (1996), Cuando una puerta se cierra, abrimos cientos. Estrategias de las familias petroleras frente al cierre de la refinería 18 de Marzo, tesis de doctorado en antropología, Facultad de Filosofía y Letras de la Universidad $\mathrm{N}$ acional Autónoma de M éxico, M éxico.

(1998), El último recurso: Ias relaciones familiares como alternativas frente a la crisis, ponencia presentada en el Congreso Internacional de LASA (Latin American Studies Association), Chicago.

Benería, Lourdes y M artha Roldán (1987), Las encrucijadas de clase y género. Trabajo a domicilio, subcontratación y dinámica de la unidad doméstica en la ciudad de M éxico, El Colegio de M éxico-Fondo de Cultura Económica, M éxico.

Bourdieu, Pierre (1988), La distinción, Taurus, M adrid.

(1990), Sociología y cultura, Grijalbo-Consejo N acional para la Cultura y las Artes, M éxico.

Carrasco, Guillermo (1998), “Q uinceañera: organización, cooperación y reciprocidad familiar", en Raúl Jiménez Guillén (comp.), Familia: una construcción social, Universidad Autónoma de Tlaxcala, Tlaxcala, pp. 171-192.

Chiarello, Franco (1994), “Economía informal, familia y redes sociales", en René M illán (comp.), Solidaridad y producción informal de recursos, Instituto de Investigaciones Sociales de la Universidad N acional Autónoma de M éxico, M éxico, pp. 179-231.

Dahrendorf, Ralph (1979), L as clases social es y su conflicto en la sociedad industrial, Rialp, M adrid.

Douglas, M ary y Baron Isherwood (1990), El mundo de los bienes. H acia una antropología de las cosas, G rijalbo-Consejo $\mathrm{N}$ acional para la Cultura y las Artes, M éxico. 
Esteinou M adrid, Rosario (1996), Familias de sectores medios: perfiles organizativos y socioculturales, Centro de Investigaciones y Estudios Superiores en Antropología Social, M éxico.

Estrada, M argarita (1995), "G rupos domésticos extensos: un viejo recurso para enfrentar la crisis", Nueva Antropología, Universidad Autónoma M etropolitana-Iztapalapa-Gv Editores, M éxico, xIv (48): 95-106.

(1996), Después del despido. Desocupación y familia obrera, Centro de Investigaciones y Estudios Superiores en Antropología Social, M éxico.

(coord.) (1999), 1995. Familia en la crisis, Centro de Investigaciones y Estudios Superiores en Antropología Social, M éxico.

y Lucía Bazán (1997), "Los errores de diciembre y los aciertos familiares. Estrategias a la crisis", Espacios familiares: Ámbitos de resistencia y solidaridad. Premio 1996. Investigación sobre las familias y los fenómenos sociales emergentes en México, PUEg-UnAM-DIF-Conapo-UAm-Azacapotzalco, M éxico.

Foster, G eorge M . (1972), Tzintzuntzán, Fondo de Cultura Económica, M éxico.

González de la Rocha, M ercedes (1986), Los recursos de la pobreza. Familias de bajos ingresos en Guadalajara, El Colegio de Jalisco-C entro de Investigaciones y Estudios Superiores en Antropología Social-Secretaría de Programación y Presupuesto, M éxico.

(1999), “La reciprocidad amenazada: un costo más de la pobreza urbana", en Rocío Enríquez (coord.), Hogar, pobreza y bienestar en México, Instituto Tecnológico y de Estudios Superiores de O ccidente, M éxico.

y Paloma Villagómez Ornelas (2004), "La nueva soledad urbana", ponencia presentada en el xxvı Coloquio del Colegio de Michoacán, Familia y Tradición. Herencias 
tangibles e intangibles en escenarios cambiantes, 27-29 de octubre.

Grammont, Hubert Carton de (2001), El Barzón: clase media, ciudadanía y democracia, Instituto de Investigaciones Sociales de la Universidad N acional Autónoma de M éxico-Plaza y Valdés, M éxico.

Kemper, Robert V. (1976), Campesinos en la ciudad: gente de Tzintzuntzán, Secretaría de Educación Pública, col. SepSetentas, núm. 170, M éxico.

Lewis, O scar (1993), Antropología de la pobreza, Fondo de Cultura Económica, M éxico.

M auss, M arcel (1979), "El ensayo sobre el don", en M arcel M auss, Sociología y antropología, Tecnos, M adrid, pp. 155-258.

M estries, Francis (1995), “El Barzón o la radicalización de los medianos y grandes productores agrícolas", Sociológica, M éxico, x (28): 143-176.

M ingione, Enzo (1994), "Sector informal y estrategias de sobrevivencia: hipótesis para el desarrollo de un campo de investigación", en René M illán (comp.), Solidaridad y producción informal de recursos, Instituto de Investigaciones Sociales de la Universidad N acional Autónoma de M éxico, M éxico, pp. 161-177.

N utini, H ugo (1968), San Bernardino Contra, University of Pittsburg Press, Pittsburg.

Robichaux, David (2002), "El sistema familiar mesoamericano: testigo de una civilización negada", en Guillermo de la Peña y Luis Vázquez León (coords.), La antropología sociocultural en el México del milenio. Búsquedas, encuentros y transiciones, Instituto $\mathrm{N}$ acional Indigenista-Consejo N acional para la Cultura y las Artes-Fondo de Cultura Económica, M éxico. 
Selby, Henry A. et al. (1994), La familia en el México urbano. Mecanismos de defensa frente a la crisis (1978-1992), Consejo N acional para la Cultura y las Artes, col. Regiones, M éxico.

Sussman, M arvin B. y Lee G. Burchinal (1980), "La red familiar del parentesco en la sociedad urbana-industrial de los Estados Unidos", en M ichael Anderson (sel.), Sociología de la familia, Fondo de Cultura Económica, M éxico, pp. 95-133.

Taggart, James M ounsey (1975), Estructura de los grupos domésticos de una comunidad náhuatl de Puebla, Instituto N acional Indigenista-Secretaría de Educación Pública, M éxico.

Weber, M ax (1979), Economía y sociedad, Fondo de Cultura Económica, M éxico.

Recibido: 22 de julio de 2005. Reenviado: 29 de septiembre de 2005. Aceptado: 4 de octubre de 2005.

José G uadalupe Rivera G onzález labora como profesor-investigador de tiempo completo de la Coordinación de Ciencias Sociales y H umanidades de la Universidad Autónoma de San Luis Potosí, en la Licenciatura en Antropología. H a impartido clases también en la Licenciatura de Antropología Social y Etnohistoria, Escuela N acional de Antropología e H istoria, así como en la $M$ aestría en Antropología Social de la Facultad de Antropología de la Universidad Autónoma del Estado de M éxico. Es doctor en ciencias antropológicas por el Departamento de Antropología Social de la Universidad Autónoma M etropolitana, unidad Iztapalapa. Su línea de investigación: antropología, globalización y reestructuración sociocultural de la región Centro-N orte de M éxico, en particular el caso de San Luis Potosí. Se cuentan entre sus publicaciones: con Rosa Brambila Paz, "La muerte del $X$ hita", Expresión Antropológica, revista del Instituto M exiquense de Cultura, 2000; "Representación y significados actuales en el carnaval de los xhitas en Jilotepec, Estado de M éxico", Antropoformas, revista de la Facultad de Antropología de la UAEm éx, 2001; "Palenque: conservación integral a través del proceso de planificación", Informados, cuaderno de trabajo de la Dirección de 
O peración de Sitios del INAH, núm. 2, noviembre de 2001. Están también sus ponencias en el Congreso $\mathrm{N}$ acional de Investigadores sobre Familia (2000), en la Convención sobre la Protección del Patrimonio M undial, Cultural y Natural (2002), el Encuentro Regional de la Asociación M exicana de Estudios del Trabajo (2005), y en el curso Turismo, Patrimonio, M edio Ambiente y Desarrollo Sustentable, celebrado en la Coordinación de Ciencias Sociales y H umanidades (2005). 